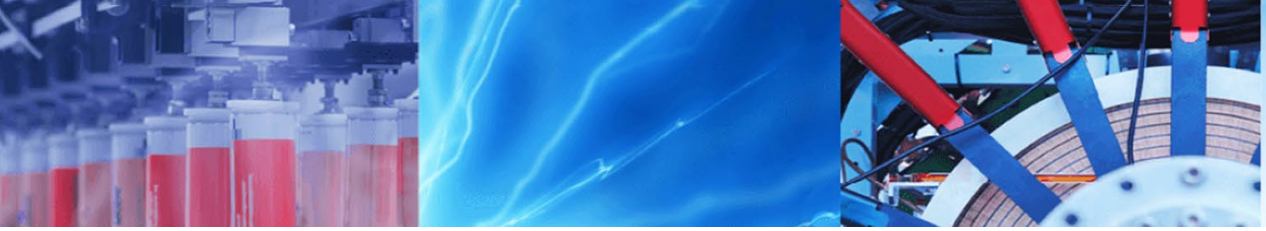

Research Article

\title{
Indoor and outdoor cultivation of Chlorella vulgaris and its application in wastewater treatment in a tropical city-Bangkok, Thailand
}

\author{
Nilay Kumar Sarker ${ }^{1}$ P. Abdul Salam ${ }^{1}$
}

Received: 21 May 2019 / Accepted: 15 November 2019 / Published online: 20 November 2019

(c) Springer Nature Switzerland AG 2019

\begin{abstract}
This study was carried out to assess the effectiveness of algal growth cultivated in photobioreactors (PBRs) in different conditions in a tropical environment, i.e., indoor and outdoor conditions with wastewater in Bangkok. The PBRs were inoculated with pure Chlorella vulgaris, and the cultivation was conducted in housing state wastewater. The productivity of $C$. vulgaris was found to be $0.0960 \mathrm{~g} / \mathrm{l} / \mathrm{d}$ in a pH-controlled outdoor PBR with $\mathrm{pH}$ in between 7.0 and $8.0,0.0618 \mathrm{~g} / \mathrm{l} / \mathrm{d}$ in outdoor PBR with no control, and $0.0131 \mathrm{~g} / \mathrm{l} / \mathrm{d}$ in indoor $\mathrm{pH}$-controlled PBR (with a fixed $\mathrm{pH}$ of 7.5). Chlorella vulgaris did not show growth in indoor PBR with no pH control. Indoor PBRs consumed 232 to 270 times more energy and needed 25 to 57 times more capital cost, and 3.8 to 16.8 times more operating cost than that of outdoor PBRs. Outdoor PBRs showed better nutrient removal efficiency of housing state wastewater than that of the wastewater treatment plant, i.e., $100 \%$ removal of biological oxygen demand, chemical oxygen demand, total phosphorus and more than $96 \%$ removal of total nitrogen; However, required time and energy consumption were more in outdoor PBRs. The possibility of improving the process performance by controlling $\mathrm{pH}$, by supplying $\mathrm{CO}_{2}$ from additional source, and by supplying continuous aeration appears as an attractive option. Although precautions should be taken for $\mathrm{CO}_{2}$ supply, high concentration $\mathrm{CO}_{2}$ caused a significant drop in $\mathrm{pH}$ and an increase of total dissolved solids. Light transmission efficiency of PBR material polyethylene terephthalate material was $85.45 \%$ to $92.08 \%$, and efficiency decreased with the increase in light intensity.
\end{abstract}

Keywords Chlorella vulgaris · Indoor cultivation · Outdoor cultivation · Wastewater · Bioremediation · Tropical city

\section{Introduction}

Microalgae is a promising feedstock and raw material for bioenergy, animal feed, fish feed, human food supplement, medicine, cosmetics products, etc. [1-4]. Microalgae can be cultivated in any place where enough nutrients, tolerable temperature, and adequate sunlight are available. Even in the places where edible crops cannot be cultivated like non-fertile lands, rocks, hilly areas and on rooftops, microalgae can be cultivated $[5,6]$. Like every other plant, $\mathrm{CO}_{2}$ is one of the necessary nutrients for the growth of microalgae. Therefore algal biomass production systems can be an effective means of $\mathrm{CO}_{2}$ sequestration [7]. Sources of $\mathrm{CO}_{2}$ can be the atmosphere, industrial flue gas, untreated raw biogas or raw natural gas from gas wells, etc. The algal cultivation process can potentially replace the traditional $\mathrm{CO}_{2}$ removal processes from gas streams where chemicals like amine solvents are used [8].

Among the possible existence of around one million algal species, only around seventy-two thousand species have been identified so far, and about forty-four thousand species were characterized [9]. Among the characterized species Chlorella strains are considered as potential sources of biofuel because they contain high protein and

$\triangle$ Nilay Kumar Sarker, nilay.en.ait@gmail.com | ${ }^{1}$ Energy Program, Department of Energy, Environment and Climate Change; School of Environment, Resources and Development, Asian Institute of Technology, P.O. Box 4, 58 Phaholyothin Road, Khlong Luang,

Pathum Thani 12120, Thailand. 
lipids under unfavorable cultivation conditions like limited nutrients, very high or deficient temperature, or light intensity [10]. Commercial production of Chlorella can be conducted with both freshwaters with fertilizer or with wastewater. Microalgae consume pollutants of wastewater as growth nutrients such as ammonium, nitrate, nitrite, phosphate, and organic carbon and reduce or remove them during algal cultivation. Integration of wastewater with algal cultivation not only treats wastewater but also offers several benefits like reduction of water footprint and cost as using freshwater and fertilizers or any other nutrients will become inessential.

Microalgae cultivation can be classified broadly into two major categories, i.e., cultivation in Ponds and PBRs. The distinctive characteristics between an open pond system and a PBR are that cultivation in ponds mostly depends on natural resources, whereas PBRs are operated in a controlled environment. An example is given in Figs. 1 and 2. Light enters the pond from the top side only (Fig. 1). Figure 2(1), (2) represents morning and afternoon, respectively. Figure 2 shows that light enters the PBR from all sides except bottom all day round causing more efficient light distribution in the PBR. The PBR requires higher capital and operating cost than that of the pond; as of now $90 \%$ of total microalgae is produced commercially in ponds $[11,12]$. The cultivation cost can be reduced by installing PBRs in outdoor. The practicality of outdoor PBRs depends on geography and weather. Some small to medium scale entrepreneurs' have come up with innovative ideas of microalgae production in developing countries in tropical regions. For example, EnerGaia, a startup from Bangkok grows Spirulina on rooftops in 15- to 20-I cylindrical PBRs and sells Spirulina as an edible product. PBRs are receiving more attention from algal researchers,

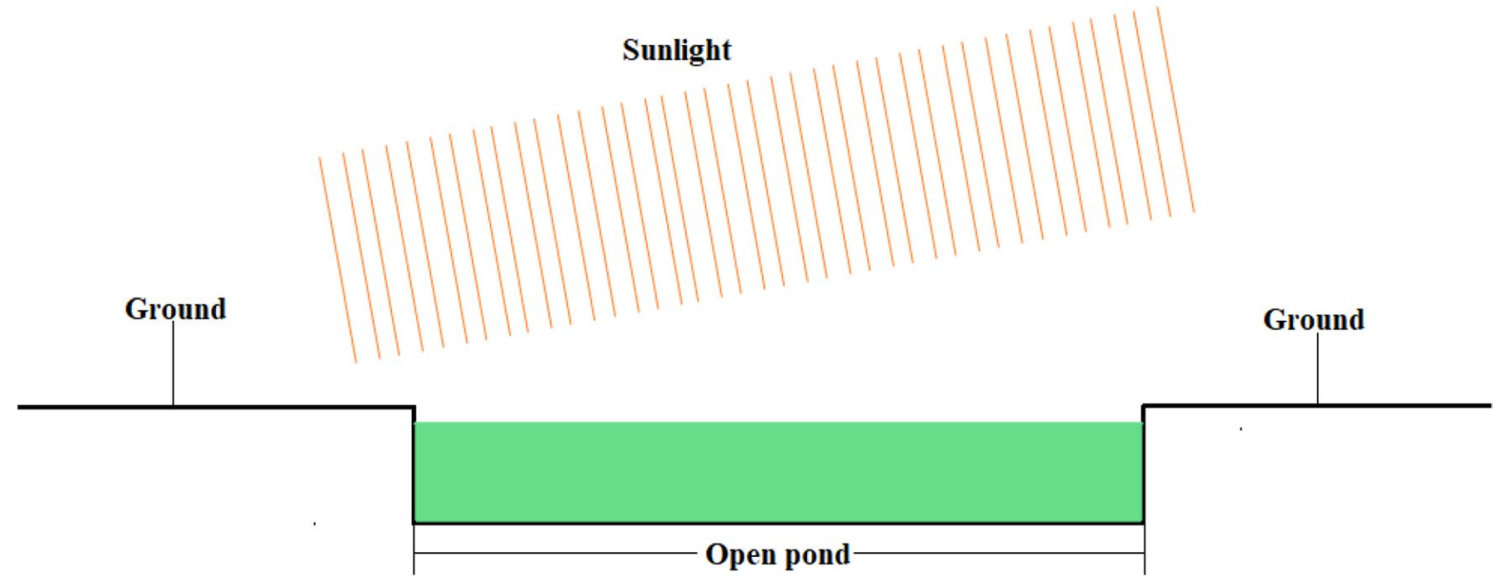

Fig. 1 Schematic diagram of open pond
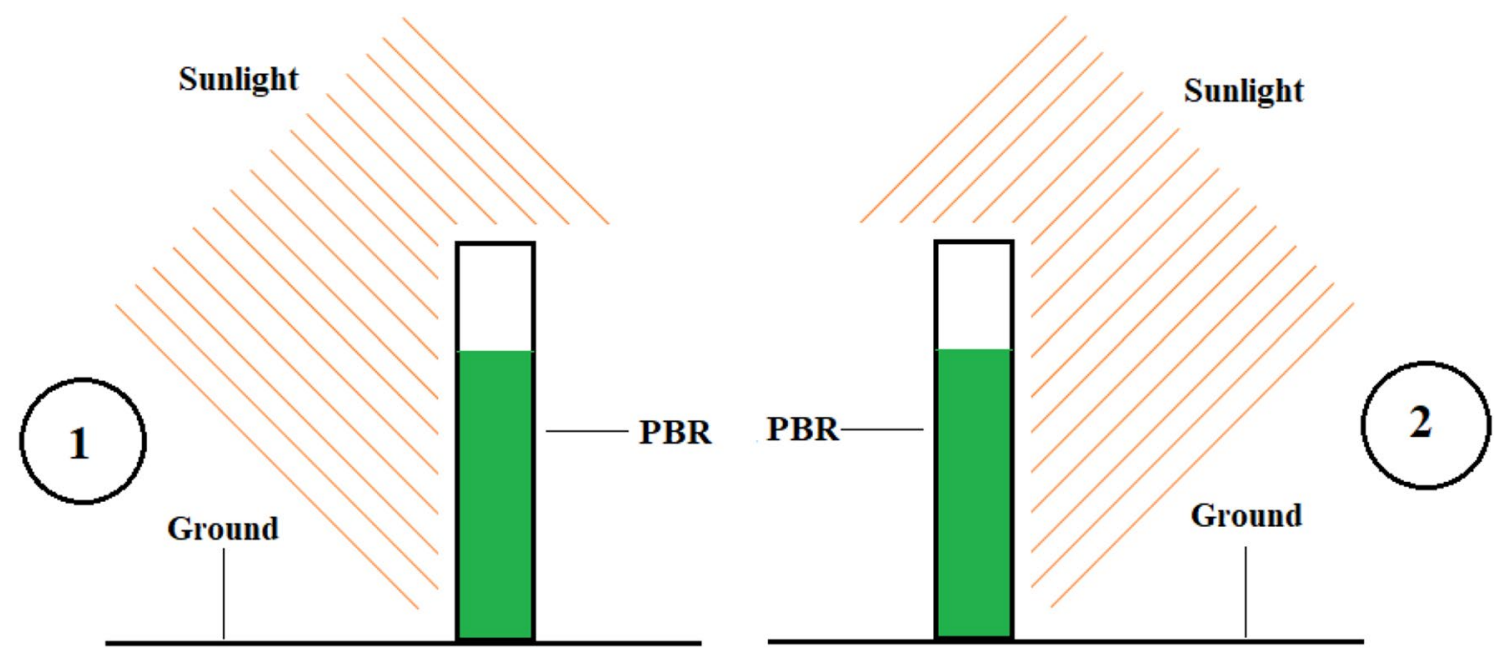

Fig. 2 Schematic diagram of a PBR kept in outdoor, where sunlight is available from sunrise to sunset. The position of the sun in the morning (1) is opposite of the afternoon (2), but PBR receives sunlight in both conditions 
and simple PBRs are used in small to medium scale commercial production.

The tropical regions receive abundant sunlight and adequate temperature providing favorable conditions for outdoor microalgae cultivation. Nevertheless, enough research has not been undertaken to assess microalgae cultivation in outdoor PBRs in tropical regions. As living organisms, microalgae are sensitive to changes in weather. Results obtained from the experiments on microalgae conducted in cold regions may not be useful in tropical weather conditions. Lack of adequate knowledge and data is one of the barriers to the expansion of commercial production of algae in tropical regions. This study attempts to help to fill in this gap. In this study, the experiments were conducted in simple PBRs with housing state wastewater in Bangkok, the capital city of Thailand, a country with a tropical climate. In Thailand, housing state wastewater is a subclassification of municipal wastewater. Only less than one-fourth of municipal wastewater generated in Thailand goes through the wastewater treatment process. Successful microalgae cultivation with wastewater can open new potentialities to address wastewater-related concerns in Thailand as well as other developing countries in tropical regions. The mean dry bulb temperature of Bangkok ranges from 28.46 to $30.23^{\circ} \mathrm{C}$, and the relative humidity is between 70 and $76 \%$ [13]. The monthly average sunshine hours are from 3.58 to $9.55 \mathrm{~h} /$ day, and the range of monthly average Global Solar Radiation (GSR) is in between 5.64 and $22.53 \mathrm{MJ} / \mathrm{m}^{2} /$ day [14]. Chlorella vulgaris shows satisfactory growth in between 20 and $40^{\circ} \mathrm{C}$, which makes it a viable option for the weather of Bangkok [15]. Although Chlorella vulgaris (C. vulgaris) is mixotrophic, it has shown satisfactory algal biomass and lipid productivity in autotropic and heterotropic conditions as well [16]. This study showcases the comparison of the productivity of microalgae, laboratory-scale capital costs, operating costs and energy consumption of cultivation for both indoor and outdoor systems for $C$. vulgaris. We compared the bioremediation efficiency of algal cultivation system with the traditional water treatment plant. In this study, we also analyzed other engineering problems related to algal cultivation, i.e., $\mathrm{CO}_{2}$ supply, aeration, and light transmission efficiency.

\section{Materials and methods}

\subsection{Microalgae sample}

Pure C. vulgaris strain was collected from the Thailand Institute of Scientific and Technological Research (TISTR), and then, it was kept in $\mathrm{N}-8$ medium in a dark place at $4{ }^{\circ} \mathrm{C}$.

\subsection{PBRs and experimental conditions}

Chlorella vulgaris cultivation experiments were conducted with twelve identical vertical tubular-shaped PBRs of $16.5 \mathrm{~cm}$ diameter and 6 I volume made of transparent PET material. The volume of the inoculum of the culture media of each PBR was 4 I. Four parameters, i.e., temperature, $\mathrm{pH}$, light intensity, and day/night cycle were considered in this experiment. All the parameters were controlled in three PBRs installed in indoor; they were labeled as PBR1. All the parameters except $\mathrm{pH}$ were controlled in another three indoor PBRs labeled as PBR2. In three outdoor PBRs labeled as PBR3 only pH was controlled, and none of the parameters were controlled in three PBRs labeled as PBR4. Cultivation of $C$. vulgaris was started in all PBRs on the same date and same time. $\mathrm{pH}$ controller was used to control pH in PBR1 s. pH was controlled manually in PBR3 s, pH was checked every day and then adjusted to 7.5 with $\mathrm{NaOH}$ solution. Each of PBR1, PBR2, PBR3, and PBR4 were labeled with three PBRs. The results found for each of PBR1, PBR2, PBR3, and PBR4 in this study were the average of the respective three PBRs.

\subsection{Wastewater}

Untreated and unsterilized wastewater used in this experiment collected from the Wastewater Treatment Plant at the Asian Institute of Technology (AIT). Its wastewater treatment capacity is $1500 \mathrm{~m}^{3} /$ day. Untreated and treated wastewater quality of the AIT wastewater plant and wastewater standards for the housing state in Thailand are provided in Table 1. Wastewater was kept unstirred for 20 min before placing it into PBRs for the experiment. Solid particles were settled down at the bottom of collector jar, and low-density black substances were floating at the top. The settled down and floating solid substances were separated with filter (made of clothes), and then, the rest of the unsterilized wastewater was filtered and then placed into PBRs for the experiment.

\subsection{Indoor experimental setup}

In a large dark room, three sets of similar experimental setup were installed. In indoor for every setup, PBR1 and PBR2 were kept at one foot distance from each other. Four lamps with white fluorescent bulbs were put at four sides of the PBRs in such a way that both PBRs received the same light intensity of $1515 \mathrm{~lx}$. Light intensity was measured with a "Light meter."The day/night cycle was $16 / 8$, i.e., the PBRs received light for continuously $16 h$, followed by $8 h$ of continuous dark, then again $16 \mathrm{~h}$ light and $8 \mathrm{~h}$ dark. The cycle continued until the experiment was completed. The light on and off was made automated by connecting with 
Table 1 Wastewater quality of AIT wastewater plant and effluent wastewater standard of Thailand

\begin{tabular}{|c|c|c|c|c|c|}
\hline \multirow[t]{2}{*}{ Parameter } & \multirow[t]{2}{*}{ Unit } & \multicolumn{2}{|c|}{ Wastewater quality of AIT wastewater plant } & \multicolumn{2}{|c|}{ Effluent wastewater standard in Thailand } \\
\hline & & Influent & Effluent & Class A & Class B \\
\hline $\mathrm{pH}$ & - & 7.3 & 7.1 & $5.5-9.0$ & $5.5-9.0$ \\
\hline BOD & $\mathrm{mg} / \mathrm{l}$ & 26 & 7.7 & $<30$ & $<20$ \\
\hline COD & $\mathrm{mg} / \mathrm{l}$ & 107 & 10 & $<120$ & $<120$ \\
\hline TSS & $\mathrm{mg} / \mathrm{l}$ & 81 & 11 & $<40$ & $<30$ \\
\hline TDS & $\mathrm{mg} / \mathrm{l}$ & 328 & 288 & 500 & 500 \\
\hline Oil and grease & $\mathrm{mg} / \mathrm{l}$ & 6.2 & $<2.0$ & $<20$ & $<20$ \\
\hline TKN & $\mathrm{mg} / \mathrm{l}$ as $\mathrm{N}$ & 16.62 & 4.49 & $<35$ & $<35$ \\
\hline Sulfide & $\mathrm{mg} / \mathrm{l}$ as $\mathrm{H}_{2} \mathrm{~S}$ & $<0.03$ & $<0.03$ & $<1.0$ & $<1.0$ \\
\hline Settleable solids & $\mathrm{mg} / \mathrm{l}$ & $<0.05$ & $<0.05$ & $<0.5$ & $<0.5$ \\
\hline Sample condition & (Observation) & Light yellow, cloud & Light yellow, clear & Light yellow, clear & Light yellow, clear \\
\hline
\end{tabular}

According to the Thai regulations, if the origin of wastewater is a residential area, it is called housing state wastewater. If the residential area consists of 500 housing units or less, then the produced housing state wastewater is classified as Class A, and for more than 500 housing units, it is Class B

timers. The indoor room temperature was set fixed at $25^{\circ} \mathrm{C}$. Air was supplied to both PBRs with an air pump at a rate of 1.0 volume per minute (vvm). If 1-I of air passes through 1-I of the liquid medium in $1 \mathrm{~min}$, it will be expressed as $1 \mathrm{vvm}$. The air velocity was measured with the "Hot Wire Anemometer" (DA-47). A schematic diagram of a single indoor setup is reported in Fig. 3.

\subsection{Outdoor experimental setup}

Three sets of similar experimental setup were employed for outdoor setup. In outdoor for every setup, two PBRs (PBR3 and PBR4) were installed under a roof. The roof was to protect the PBRs from rain but was high enough not to block sunlight. Air was supplied to the PBRs at a rate of $1.0 \mathrm{vvm}$. A schematic diagram of a single outdoor setup is shown in Fig. 4.

\subsection{Algal density measurement}

Separation of microalgae with filter paper was difficult at low algal density in the cultivation medium as indicated by the light green color of the medium. In this particular case, optical density (OD) of the medium was measured with a spectrophotometer at $420 \mathrm{~nm}$ (nanometer). When the color of the medium turned to dark green indicating a considerable increase of algal density, both spectrophotometer and filter paper were used. In case of using filter paper, at first weight of filter paper $(f 1)$ was measured in grams. Then samples $(v)$ were collected from PBRs and then filtered. Filtration left only wet algae on filter paper; the filter paper with wet microalgae was then dried with a solar drier. The weight of the dried filter paper with microalgae ( $f 2$ ) was measured in grams. Mass of microalgae was found by subtracting $f 1$ from $f 2$. Depending on the color of the medium, amount of sample can be 50 to $100 \mathrm{ml}(\mathrm{v})$, i.e., for dark green sample $50 \mathrm{ml}$ was enough, but for light green sample, more volume was required to measure the mass of algae $(f 2-f 1)$ accurately. Then algal density $(g / l)$ was measured by Eq. (1). In Eq. (1) $f 1$ and $f 2$ are in grams, and $\mathrm{v}$ is in $\mathrm{ml}$.

Algal density $(g / l)=((f 2-f 1) / v) \times 1000$

Algal densities of light green mediums were calibrated from OD using the values of algal densities with their respective ODs of dark green mediums. If OD of the light green medium is $x 1$ and ODs and algal densities of two dark green medium are $x 2$ and $x 3$, and $y 2$ and $y 3$, respectively; algal density of light green medium $y 1$ is calculated by the linear interpolation Eq. (2).

$(y 1-y 2) /\left(y 2-y^{3}\right)=(x 1-x 2) /(x 2-x 3)$

\subsection{Wastewater quality}

AIT wastewater treatment plant provided data of BOD and COD of the treatment plant's influent and effluent. TN is the summation of total Kjeldahl nitrogen (TKN), nitrate, and nitrite. TKN, nitrate, nitrite, and TP were measured in the laboratory by following the standard procedure described in APHA [17]. After bioremediation with algal cultivation, BOD was measured by using the 5-day BOD test method, and COD was measured by using the closed reflux titrimetric method. These are standard testing methods described by APHA [17]. The removal efficiency of $B O D, C O D, T N$, and TP was estimated from the absolute 


\section{Air Conditioner}

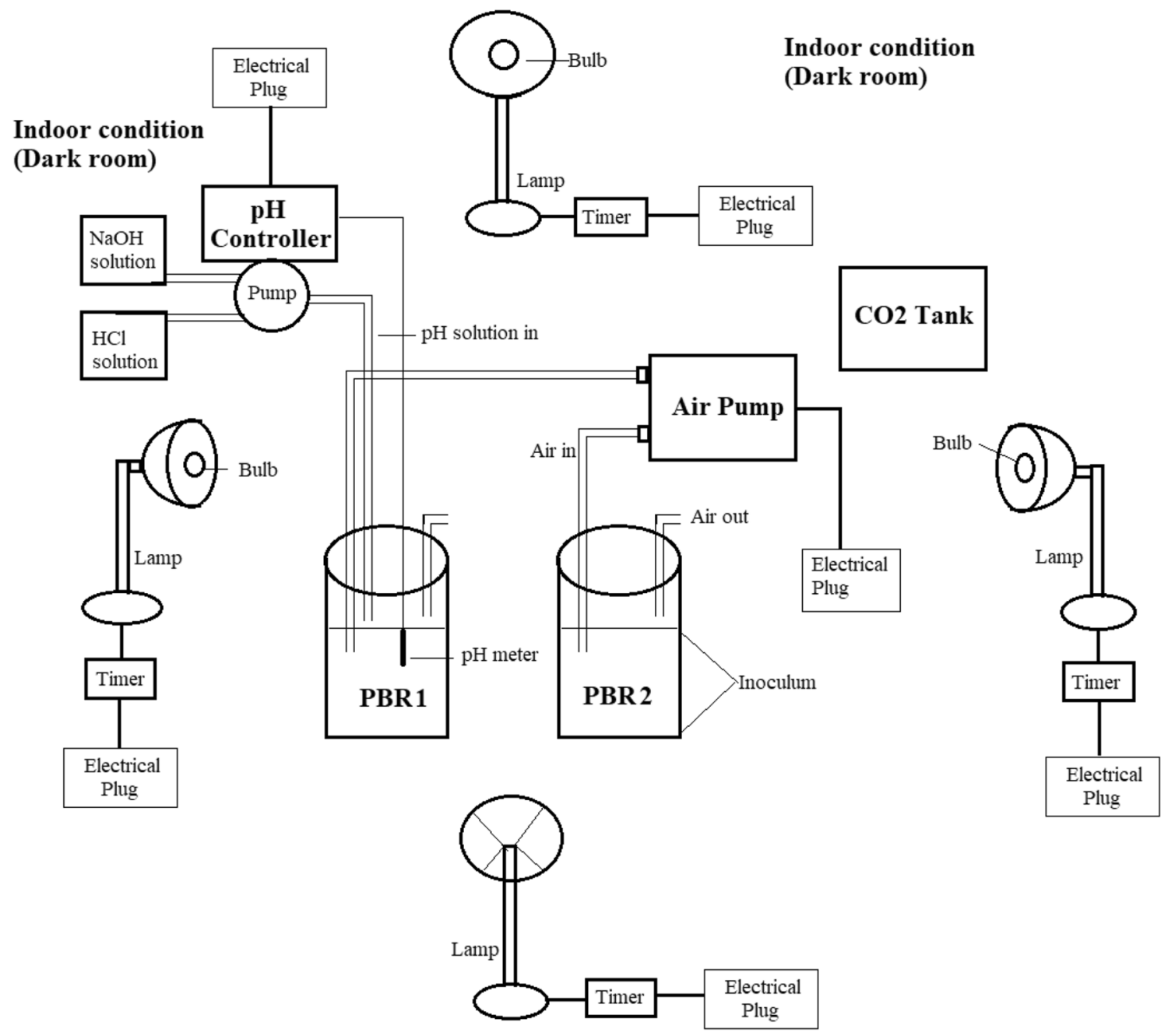

Fig. 3 Schematic diagram of a single indoor setup. Note A total of three setups were employed for indoor experiments. Every pair of lamps standing against each other was at the same distance from the PBRs; however, it was not appropriately resembled in the diagram to make visible every equipment and component of the diagram. During $\mathrm{CO}_{2}$ supply, the air pump was replaced by the $\mathrm{CO}_{2}$

value of BOD, COD, TN, and TP of wastewater before and after algal cultivation.

\subsection{Other measurements}

Digital pH meter (YIERYI Digital pH Pen), "Humidity/Temperature meter" (model-Digicon HT-776), and "Light meter" (model-Digicon LX-73) were used to measure $\mathrm{pH}$, temperature, and light intensity, respectively. "Light Meter" shows light intensity in lux, Klux, or mega-lux. tank. After the five minutes of the $\mathrm{CO}_{2}$ supply, the air pump was reinstalled again immediately. Both acidic and alkaline solutions were set with an automatic $\mathrm{pH}$ controller. As the $\mathrm{pH}$ of the culture tended to decrease, the acidic solution was not needed to be used by the $\mathrm{pH}$ controller

Energy consumption of air pumps, lamps, and pH controller was measured with "Energy Logger" (model—Voltcraft 4000F) and of the air conditioner with "Electricity Monitoring Transmitter" (model-Efergy C $\in 0560$ FC). In the case of measuring the light transmission efficiency of the PBRs, at first light intensity was measured without installing PBR. Then the PBR was installed, and a sensor of the lux meter was inserted in empty PBR, and light intensity was measured again. The light transmission efficiency of the PBR material was calculated using these two values of 


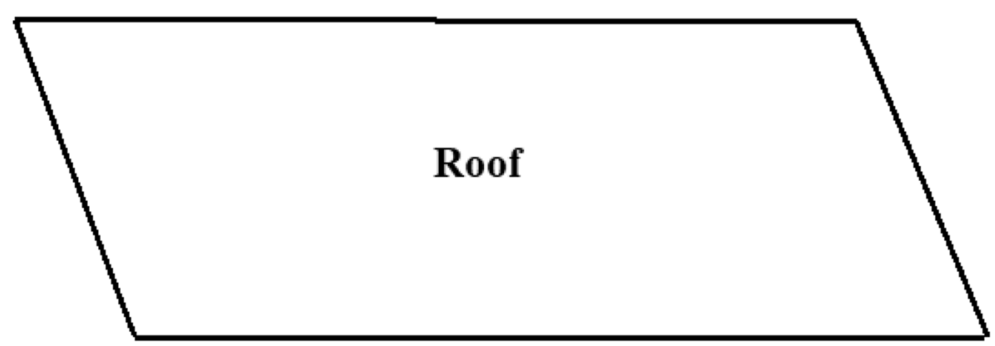

\section{Outdoor condition \\ Outdoor condition}

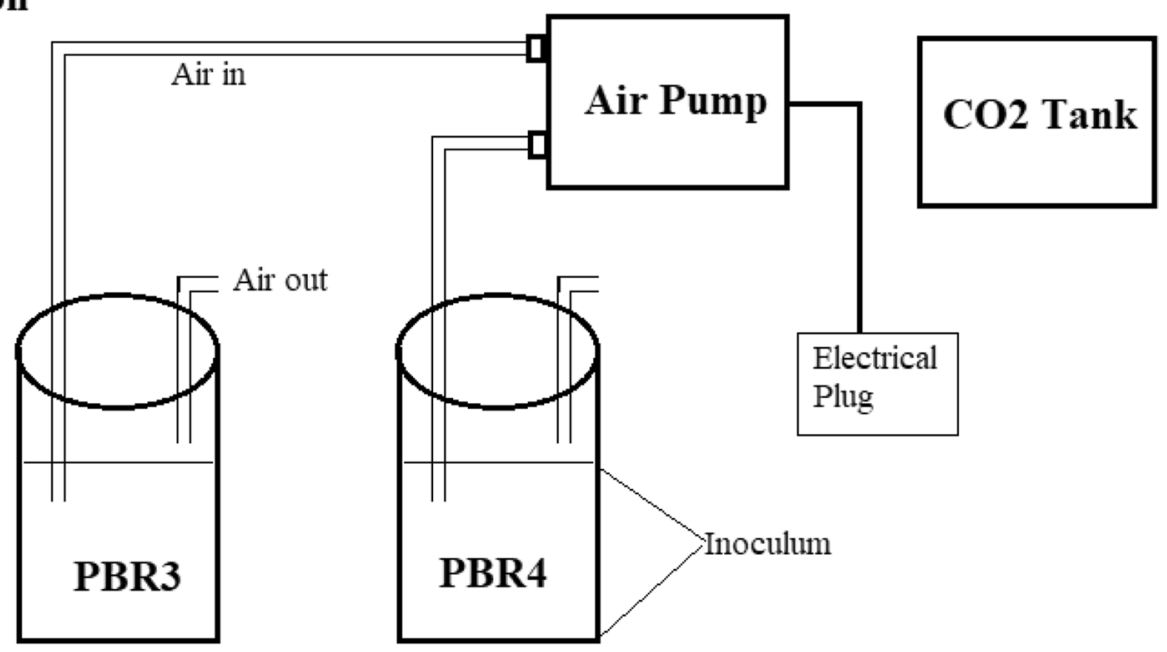

Fig. 4 Schematic diagram of a single outdoor setup. Note A total of three setups were employed for outdoor experiments. Same as the indoor experiment, the air pump was replaced by a $\mathrm{CO}_{2}$ tank

light intensity. Irradiance units were converted from lux to $\mu \mathrm{mol} / \mathrm{m}^{2} \mathrm{~s}$ and vice versa according to the guidelines of Thimijan and Heins [18].

\section{Result and discussion}

\subsection{Algal growth}

Figure 5 reports the growth trend of $C$. vulgaris in PBR1, PBR2, PBR3, and PBR4. Maximum biomass density, specific growth rate, and productivity of $C$. vulgaris attained in PBR1 was $0.131 \mathrm{~g} / \mathrm{l}, 0.11 / \mathrm{d}$, and $0.0131 \mathrm{~g} / \mathrm{l} / \mathrm{d}$, respectively. Maximum biomass density was achieved on the 10th day. The lag phase for PBR1 was 2 days, as algal growth was not observed during the first 2 days. After reaching maximum biomass density, the stationary phase continued up to the 12th day, and then, biomass density started declining. PBR2 was monitored for more than 20 days, and no algal growth was found.

Best algal growth was acquired in PBR3. Maximum biomass density, specific growth rate, and productivity of C. vulgaris obtained in PBR3 was $0.384 \mathrm{~g} / \mathrm{l}, 0.251 / \mathrm{d}$, and $0.096 \mathrm{~g} / \mathrm{l} / \mathrm{d}$, respectively. No lag phase was observed in during $\mathrm{CO}_{2}$ supply. After 5 min of the $\mathrm{CO}_{2}$ supply, the air pump was reinstalled again immediately

PBR3; algal growth was observed from the first day. Maximum biomass density was achieved on the 4th day, and biomass density started declining from the next day. Maximum biomass density, specific growth rate, and productivity of C. vulgaris obtained in PBR4 was $0.371 \mathrm{~g} / \mathrm{l}, 0.167$ 1/d, and $0.0612 \mathrm{~g} / \mathrm{l} / \mathrm{d}$, respectively. Biomass density reached to highest on the 6th day and started dropping from the 8th day.

Significantly higher maximum biomass density, specific growth rate, and productivity were found in the outdoor PBRs than that of the indoor BRs. Except for light intensity, temperature, and day/night cycle was set to at optimum conditions in the indoor system, given that optimum light intensity for $C$. vulgaris is $60-100 \mu \mathrm{mol} / \mathrm{m}^{2} \mathrm{~s}$ (3240 Ix to $5400 \mathrm{~lx}$ ) [19]. The sunlight intensity exceeded optimum condition by several folds, and indoor light intensity was less than half of optimum light intensity. Both low and excess light limit algal growth. This experiment suggests that insufficient light intensity negatively affects algal growth more than excess light intensity. Among the indoor PBRs, microalgae did not grow in the PBR2, whereas algal growth was found in the PBR1. Among the outdoor PBRs, PBR3 displayed better algal density and growth rate than the PBR4. The growth difference between PBR1 and 
Fig. 5 Growth trend of $C$. vulgaris in PBR1, PBR2, PBR3 and PBR4

\section{Algal growth trend in PBR1, PBR2, PBR3 and PBR4}

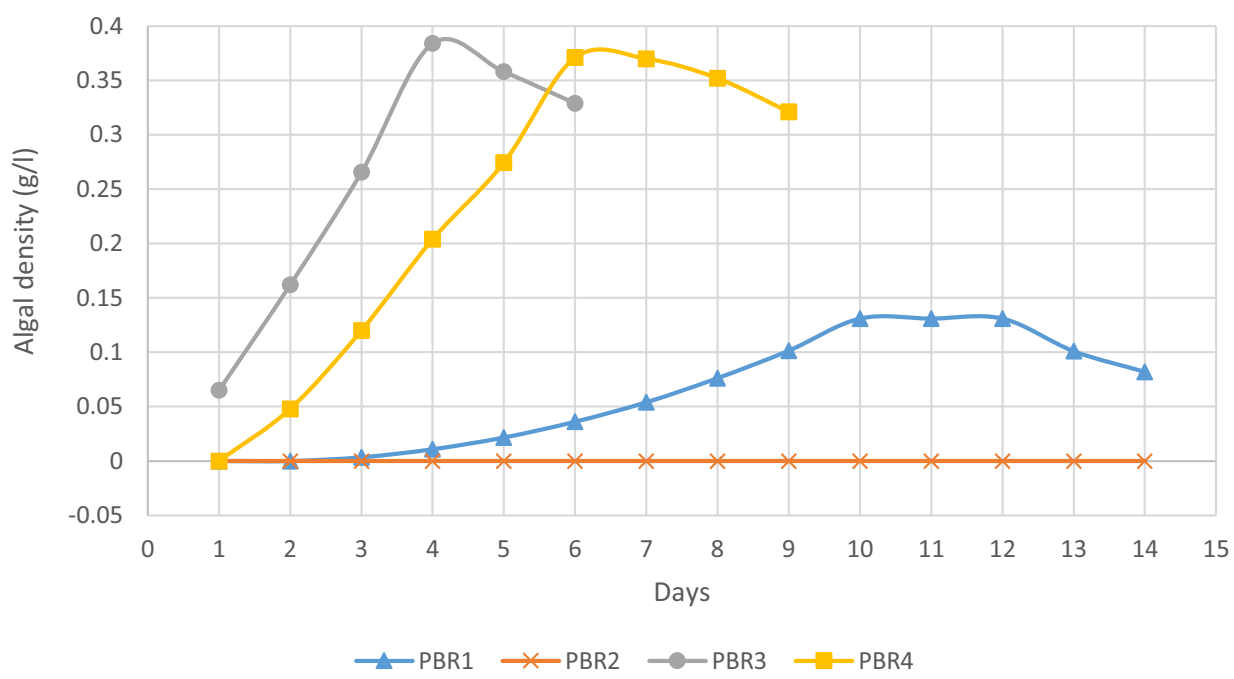

PBR2 and between PBR3 and PBR4 proves the effectiveness of $\mathrm{pH}$ control.

Singh et al. [20] conducted an indoor experiment with 250-ml bottles. In their experiment, maximum algal density of $C$. vulgaris was $1.09 \mathrm{~g} / \mathrm{l}$ and productivity was $0.17 \mathrm{~g} / \mathrm{l} / \mathrm{d}$ in controlled Bold's Basal medium, whereas with wastewater and no $\mathrm{pH}$ control, algal density was $1.13 \mathrm{~g} / \mathrm{l}$ and productivity was $0.19 \mathrm{~g} / \mathrm{l} / \mathrm{d}$. Frumento et al., (2013) reported a specific growth rate of $0.2891 / \mathrm{d}$ and a productivity of $33.4 \mathrm{mg} / \mathrm{l} / \mathrm{d}$ with $5 \mathrm{Klux}$ light intensity. The above findings suggest that the possible reasons of PBR1's low productivity and PBR2's failure were not employing optimum light intensity (because of lack of adequate facility) and using large PBRs $(16.5 \mathrm{~cm}$ diameter and 4 I culture medium). However, it should be noted that PBRs with large diameter and size are used for commercial practices. Lam and Lee [21] conducted large-scale indoor and outdoor $C$. vulgaris cultivation in freshwater with an organic fertilizer in Malaysia, which is a tropical country. They found $0.28 \mathrm{~g} / \mathrm{l}$ of maximum of density and $21.8 \mathrm{mg} / \mathrm{l} / \mathrm{d}$ of productivity in the outdoor cultivation system, which was less than our experiment. In the indoor cultivation system, algal density was $0.52 \mathrm{~g} / \mathrm{l}$, and productivity was $0.032 \mathrm{~g} / \mathrm{l} / \mathrm{d}$, which was significantly higher than of the results found in our indoor cultivation systems. The use of sequential baffled PBR, 5\% continuous supply of $\mathrm{CO}_{2}$, and optimum light condition in their experiment contributed to achieving better productivity than ours in indoor conditions.

\subsection{Indoor and outdoor algal cultivation conditions}

The algal growth in the indoor PBRs (PBR1 + PBR2) was not influenced by the outdoor conditions because light intensity, day/night cycle, and temperature of indoor experiments were controlled. The light transmission efficiency of the PET indoor was $92.08 \%$. Algal growth in outdoor PBRs (PBR3 and PBR4) was monitored for 8 days. The weather condition during those days has been shown in Table 2. Temperature and light intensity varied from 24 to $41^{\circ} \mathrm{C}$ and 4559 to 68,193 Ix, respectively. Sun condition
Table 2 Outdoor weather conditions

\begin{tabular}{|c|c|c|c|c|c|c|c|}
\hline \multirow[t]{2}{*}{ Days } & \multirow[t]{2}{*}{ Date } & \multirow[t]{2}{*}{ Weather condition } & \multicolumn{3}{|c|}{ Temperature $\left({ }^{\circ} \mathrm{C}\right)$} & \multicolumn{2}{|c|}{$\begin{array}{l}\text { Direct sun light intensity } \\
\text { (lux) }\end{array}$} \\
\hline & & & 11 a.m. & 4 p.m. & 11 p.m. & 11 a.m. & 4 p.m. \\
\hline 1 & $14-01-2018$ & Moderate sunny & $25.4 \pm 0.1$ & $28.9 \pm 0.1$ & $23.7 \pm 0.1$ & $42,599 \pm 201$ & $13,261 \pm 94$ \\
\hline 2 & $15-01-2018$ & Partly sunny & $26.7 \pm 0.1$ & $33.5 \pm 0.1$ & $24.3 \pm 0.1$ & $42,032 \pm 234$ & $4559 \pm 52$ \\
\hline 3 & $16-01-2018$ & Very sunny & $33.5 \pm 0.1$ & $38.2 \pm 0.1$ & $25.3 \pm 0.1$ & $61,994 \pm 334$ & $22,581 \pm 206$ \\
\hline 4 & $17-01-2018$ & Very sunny & $33.3 \pm 0.1$ & $36.9 \pm 0.1$ & $25.7 \pm 0.1$ & $62,409 \pm 352$ & $21,922 \pm 194$ \\
\hline 5 & $18-01-2018$ & Very sunny & $33.2 \pm 0.1$ & $34.4 \pm 0.1$ & $27.0 \pm 0.1$ & $61,503 \pm 315$ & $16,205 \pm 158$ \\
\hline 0 & $19-01-2018$ & Very sunny & $40.7 \pm 0.1$ & $37.1 \pm 0.1$ & $27.1 \pm 0.1$ & $65,547 \pm 327$ & $17,951 \pm 145$ \\
\hline 7 & $20-01-2018$ & Very sunny & $41.0 \pm 0.1$ & $35.8 \pm 0.1$ & $26.6 \pm 0.1$ & $68,193 \pm 344$ & $18,903 \pm 152$ \\
\hline 8 & 21-01-2018 & Very sunny & $39.9 \pm 0.1$ & $36.2 \pm 0.1$ & $26.5 \pm 0.1$ & $65,973 \pm 316$ & $18,439 \pm 137$ \\
\hline
\end{tabular}


affected the light intensity and temperature in the day time; however, little variation of temperature was found at night. Light transmission efficiency was examined in various weather conditions such as on a cloudy, rainy, and sunny day outdoor. In all conditions, light transmission efficiency and light intensity showed a negative correlation. For instance, when sunlight intensity was 1935 , 28,568 , and $59,822 \mathrm{~lx}$, light transmission efficiency was $90.44 \%, 87.72 \%$, and $85.45 \%$, respectively. This test was performed with PET, but with different types of materials, the result could be in varying trends. As actual amount of light received by the culture medium depends on the light transmission efficiency, a material with higher transmission efficiency requires the deployment of a light source with comparatively less intensity for indoor PBRs. The relation between transmission efficiency and sunlight intensity should be taken into account carefully during material selection for the outdoor PBRs as sunlight intensity changes all year round. Additionally, the durability of the material is also important for a long time algal production. As the transmission efficiency of PET was found to be more than $80 \%$ in every condition, it was durable for simple cultivation mechanisms and of low cost, and the PET can be a standard choice for microalgae cultivation with simple operation techniques.

\subsection{Cost analysis}

Production of microalgae is the primary purpose of commercial algal cultivation. Microalgae are separated and collected from the cultivation media after reaching its maximum density and then processed for further purposes. So, the required time to obtain the maximum biomass density only was considered for cost analysis. Table 3 reports on energy consumption and operating cost of all PBRs, and Table 4 reports on capital costs.

\subsubsection{Energy consumption}

Chlorella vulgaris did not grow in PBR2; however, energy consumption and cost of PBR2 have been discussed here. Some experiments were successfully conducted in indoor cultivation without $\mathrm{pH}$ control, e.g., experiment conducted by [20]. As microalgae in PBR1 required 10 days to reach maximum density, 10 days time period was considered for energy and cost analysis of both PBR1 and PBR2. PBR1 and PBR2 consumed 4847.3 Wh and 4185.3 Wh energy every

Table 4 Capital cost analysis of the PBRs

\begin{tabular}{|c|c|c|c|}
\hline $\begin{array}{l}\text { Cost of total indoor } \\
\text { system (PBR1 and } \\
\text { PBR2) }\end{array}$ & THB & $\begin{array}{l}\text { Cost of total out- } \\
\text { door system (PBR3 } \\
\text { and PBR4) }\end{array}$ & THB \\
\hline Air pump & 280 & Air pump & 280 \\
\hline Lamps (4 sets) & 1220 & Extension cable & 350 \\
\hline Bulb (4 sets) & 360 & Others & 110 \\
\hline Timer ( 4 sets) & 1160 & Total & 740 \\
\hline Air conditioner & 15,200 & & \\
\hline Extension cable & 770 & & \\
\hline Others & 20 & & \\
\hline $\mathrm{pH}$ controller (PBR1) & 11,570 & & \\
\hline Total & 30,580 & & \\
\hline \multicolumn{4}{|c|}{ The capital cost of each PBR } \\
\hline PBR1 & PBR2 & PBR3 & PBR4 \\
\hline 21,075 (THB) & 9505 (THB) & 370 (THB) & 370 (THB) \\
\hline
\end{tabular}

Table 3 Energy consumption and operating cost analysis of indoor and outdoor PBRs

\begin{tabular}{|c|c|c|c|c|}
\hline \multirow{2}{*}{$\begin{array}{l}\text { Parameter } \\
\text { Name of PBRs }\end{array}$} & \multicolumn{2}{|c|}{ Indoor PBRs } & \multicolumn{2}{|c|}{ Outdoor PBRs } \\
\hline & PBR1 & PBR2 & PBR3 & PBR4 \\
\hline Operating days of one complete cycle (days) & 10 & 10 & 4 & 6 \\
\hline \multicolumn{5}{|c|}{ Energy-consuming equipment and their consumption of energy } \\
\hline Air pump (Wh/day) & 18.0 & 18.0 & 18.0 & 18.0 \\
\hline Light (Wh/day) & 668.8 & 668.8 & - & - \\
\hline Temperature control (Wh/day) & 3498.5 & 3498.5 & - & - \\
\hline $\mathrm{pH}$ control (Wh/day) & 662.0 & - & - & - \\
\hline Total energy consumption (Wh/day) & 4847.3 & 4185.3 & 18.0 & 18.0 \\
\hline Total energy cost (THB) & 193.89 & 167.41 & 0.29 & 0.43 \\
\hline $\mathrm{NaOH}$ pellet cost (THB) & 100.00 & 0.00 & 40.00 & 0.00 \\
\hline $\mathrm{CO}_{2}(\mathrm{THB})$ & 32.25 & 32.25 & 12.90 & 19.35 \\
\hline Total operating cost (THB) & 336.14 & 199.66 & 53.19 & 19.78 \\
\hline
\end{tabular}

Electricity price: $4 \mathrm{THB} / \mathrm{kWh}$

Cost of $\mathrm{CO}_{2}=15 \mathrm{I} \mathrm{CO}_{2} /$ day $\times$ Operating days $\times 0.215 \mathrm{THB} / \mathrm{l}$ of $\mathrm{CO}_{2}$ $\mathrm{THB}=$ Thai Baht

$1 \mathrm{USD}=32.81 \mathrm{THB}$ (as of December 2018) 
day, respectively, and the cost due to energy consumption was 193.89 Thai Baht (THB) and 167.41 THB, respectively. The energy consumption of the automatic $\mathrm{pH}$ controller contributed to the additional energy consumption of PBR1. The $\mathrm{pH}$ of PBR1 was always kept constant at 7.5; however, the $\mathrm{pH}$ of PBR3 was maintained manually from 7.0 to 8.0 because some studies reported that for $C$. vulgaris showed satisfactory results in this range $[22,23]$. Air pumps, the only energy-consuming equipment of outdoor PBRs, were accounted for less than $0.5 \%$ of the total energy in both PBR1 and PBR2.

\subsubsection{Total operating cost}

For every cycle of cultivation, PBR4 required minimum operating cost (20 THB), and PBR3 required 2.5 times more than of PBR4. The contributing factors to the higher operating cost of the BR4 were the use of chemical $(\mathrm{NaOH})$ to control $\mathrm{pH}$ and longer duration of the cycle ( 6 days). The operating cost of PBR1 was 336 THB for one cycle, $68 \%$ higher than of PBR2. The cycle period of both indoor PBRs was considered the same. Equipment and chemicals used for automatic $\mathrm{pH}$ control in PBR1 contributed to the higher operating cost. Operating costs of PBR1 and PBR2 were 16.8 and 10 times PBR4, respectively, and 6.4 and 3.8 times PBR3, respectively. The indoor PBRs consumed significantly higher energy than of outdoor PBRs; this additional energy and more extended cycle period was conducive to the higher operating cost of indoor PBRs.

\subsubsection{Total capital cost}

Parameters of outdoor algal cultivation such as temperature, light intensity, light wavelength or light color, and day/night cycle depend on geographic conditions and weather. The advantages of indoor cultivation systems over outdoor cultivation systems are that most of these parameters are subject to control in indoor systems. The $\mathrm{pH}$ of the medium can be controlled both in outdoor and indoor systems. However, the advantages of indoor cultivation systems are bestowed utilizing capital cost and energy consumption. For example, indoor light intensity could be increased to the average outdoor intensity by increasing 20 to 30 times. However, it would also require a higher number of lamps and bulbs which would, in turn, increase the energy consumption and the cost.

In countries like Thailand, where fossil fuel is the dominant energy source, the indoor microalgae cultivation system reduces the attainability of microalgae cultivation as a potential medium of the carbon capture system. For example, In Thailand, $1 \mathrm{kWh}$ of electricity production emits $0.60 \mathrm{~kg} \mathrm{CO}_{2}$ [24]. In this study, indoor PBRs consumed 232 to 270 times more energy than of outdoor PBRs causing emission of the proportional amount of increased $\mathrm{CO}_{2}$ emission during algal growth. Outdoor systems (PBR3 and PBR4) were accounted for a total capital cost of 740 THB, whereas it was 30,580 THB for indoor systems (PBR1 and PBR2). The indoor cultivation system requires more land, infrastructure, and equipment inducing more capital costs. Figures 3 and 4 show that more area and equipment was required for two PBRs in the indoor system than of the outdoor system. However, capital cost for the roof, building, or land was not considered in this study. The cost required to protect equipment from sudden rain outdoor was reported as "Other" cost in Table 4. An equal number of pumps were deployed in both outdoor and indoor systems, but cost of pump accounted for $38 \%$ of total outdoor capital cost, whereas it contributed less than $1 \%$ of total indoor capital cost. The temperature controller (air conditioner) possessed the highest share of indoor capital cost followed by the $\mathrm{pH}$ controller, lighting system (bulb + lamp), and timer. The air conditioner contributed to half, and along with the $\mathrm{pH}$ controller contributed to $87.5 \%$ of the total indoor capital cost. Controlling temperature and $\mathrm{pH}$ with cost-effective innovative techniques would reduce total indoor costs. Among the indoor PBRs, the capital and operating cost of the $\mathrm{pH}$ controller was the reason for the difference between PBR1 and PBR2. Figure 6 reports the comparative performance of PBRs in terms of capital cost and operation cost, along with productivity.

\subsection{Effect of $\mathrm{CO}_{2}$ supply and aeration}

$\mathrm{CO}_{2}$ supply caused a $\mathrm{pH}$ drop in every PBR. In Fig. 7, pH in every PBR before and after $\mathrm{CO}_{2}$ supply is shown. From Fig. 7, it is evident that $\mathrm{pH}$ drop due to $\mathrm{CO}_{2}$ was dependent on the $\mathrm{pH}$ before the $\mathrm{CO}_{2}$ supply. The $\mathrm{pH}$ trends of after and before $\mathrm{CO}_{2}$ supply were almost parallel. For the PBRs where $\mathrm{pH}$ was not adjusted, higher $\mathrm{pH}$ was found every next day. It indicates that, below or around $7.0 \mathrm{pH}$ in the absence of $\mathrm{pH}$ control, aeration increases $\mathrm{pH}$ of the culture medium. For the first 4 days before $\mathrm{CO}_{2}$ supply, the $\mathrm{pH}$ of PBR3 where $\mathrm{pH}$ was controlled manually, was in between 7.0 and 8.0. So, both PBR1 and PBR3 maintained favorable $\mathrm{pH}$ condition throughout their respective whole cycle. In PBR2 and PBR4, pH was in between 7.0 and 8.0 for 5 th to 9 th and 3rd to 6 th days, respectively. Similar profile was found for both PBR2 and PBR4 suggesting that $\mathrm{pH}$ was not the main reason for not growing microalgae in PBR2. Rachlin and Grosso (1991) claimed that the growth rate of $C$. vulgaris dropped by $78.2 \%$ at $\mathrm{pH} 3.0,71 \%$ at $\mathrm{pH}$ 4.0, $55.5 \%$ at $\mathrm{pH} 5.0$, and $26.4 \%$ at $\mathrm{pH} 6.2$ compared to the maximum growth rate found at $\mathrm{pH} 7.5$ [23]. Some studies also suggested that frequent $\mathrm{pH}$ fluctuation can alter the lipid composition of microalgae [25-27]. TDS increased from around $30 \%$ to more than $80 \%$ with the $\mathrm{pH}$ drop in 

capital cost and operation cost for every cycle of operation of the PBRs. Note Here, the capital cost of PBR $1=[($ Cost of total indoor System except $\mathrm{pH}$ controller/2) + pH controller]; the capital cost of PBR2 $=($ Cost of total indoor System - Capital cost of PBR1), and the capital cost of PBR3 and PBR4 $=($ Cost of total outdoor System/2)
Fig. 6 Productivity, total

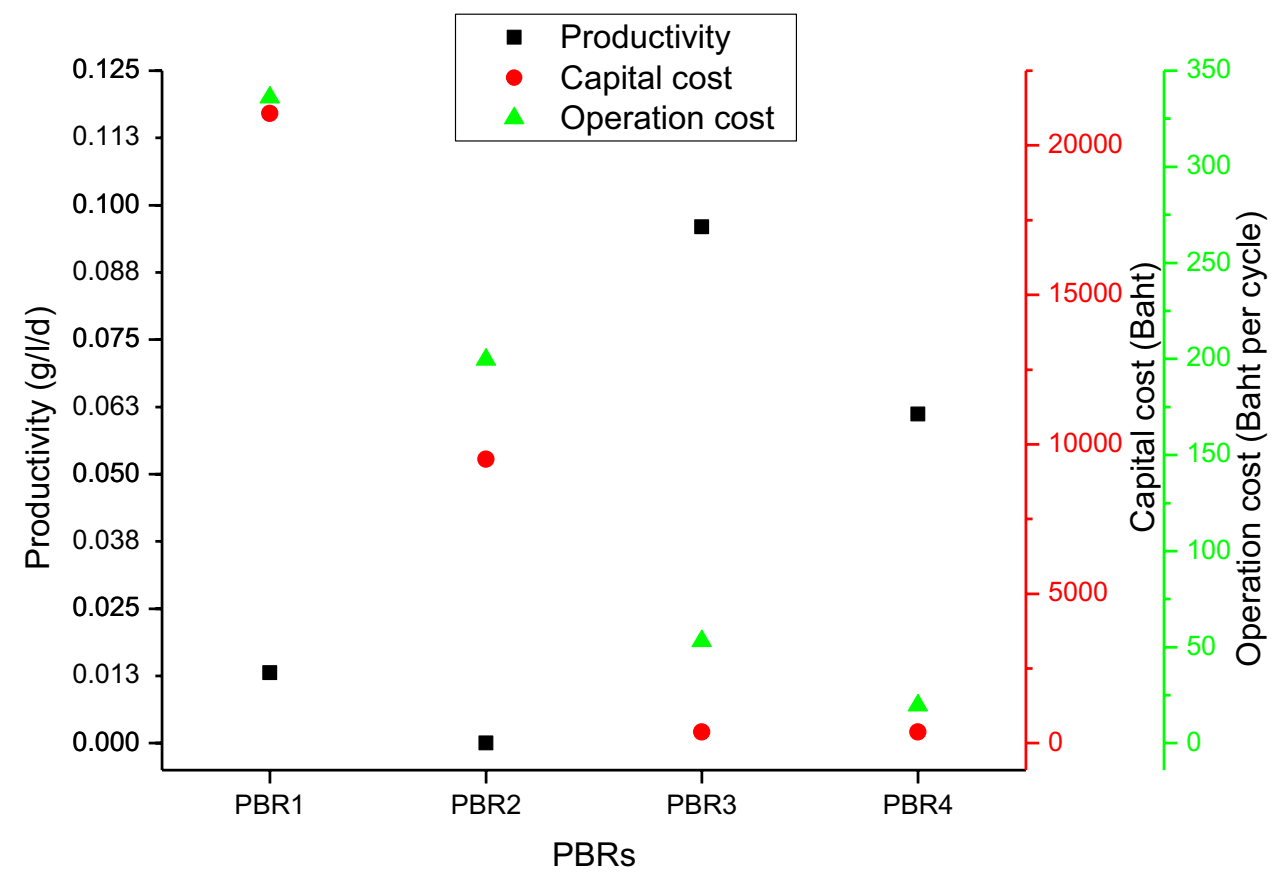

вева

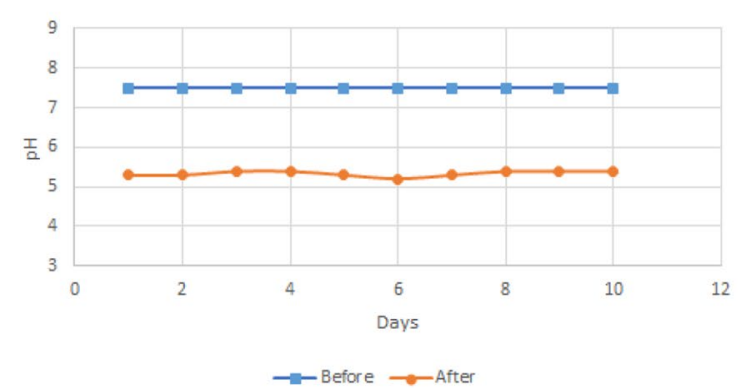

PBR2

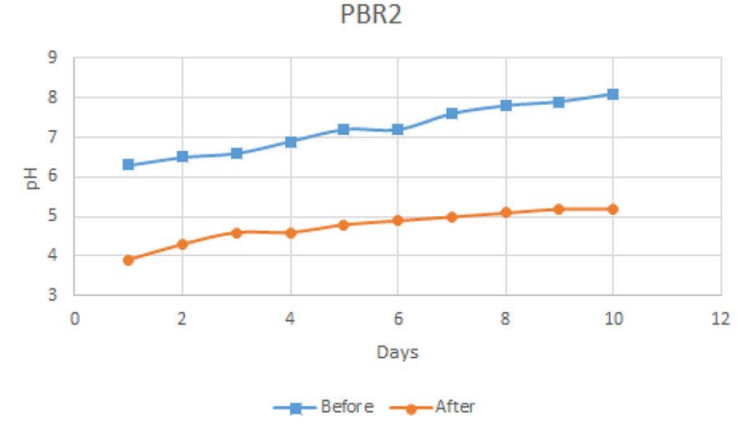

Fig. $7 \mathrm{pH}$ in the PBRs before and after the supply of $\mathrm{CO}_{2}$

every PBR but never exceeded the standard of treated wastewater effluent in Thailand ( $500 \mathrm{ppm}$ ). $\mathrm{CO}_{2}$ supply for a long time would cause further $\mathrm{pH}$ drop, which would inhibit the algal growth and further increase of TDS. If the cultivation mechanism requires $\mathrm{CO}_{2}$ supply for a more extended period or continuously, $\mathrm{CO}_{2}$ can be supplied very low concentrations to prevent rapid pH drop, e.g.,
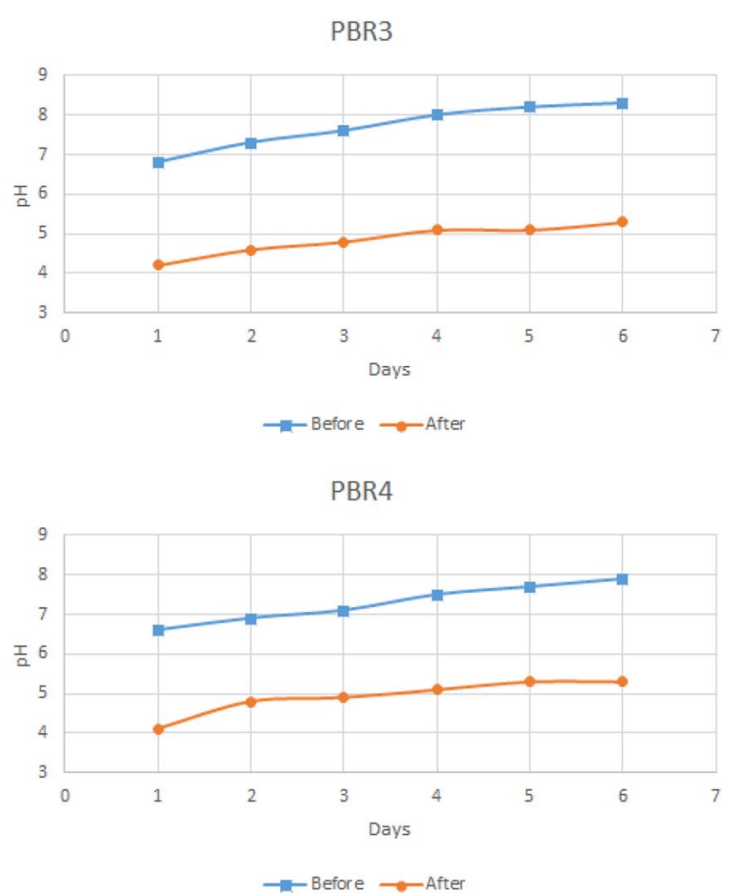

Cuellar-Bermudez et al. (2015) reported that continuous aeration with $5 \% \mathrm{CO}_{2}$ kept $\mathrm{pH}$ of the medium between 7.0 and 8.0 [28].

Aeration was provided continuously to agitate medium to prevent microalgae culture from self-shading especially at higher algal density. Aeration was also a source of atmospheric $\mathrm{CO}_{2}$. The absence of aeration caused settling 
down of the algal cells to the bottom of the PBRs at high algal density. Algal cells settled down in light green cultures when aeration was halted for 10 to $12 \mathrm{~h}$; however, the algal cell settling down required 10 to $12 \mathrm{~min}$ at the absence of aeration in dark green medium. Keeping culture medium unstirred for a long time also caused algal cells to adhere to the PBR wall hindering light entrance into PBR. In this particular condition, the start of aeration again did not unfasten most of the cells on the wall; the wall needed cleaning. However, cleaning the wall in the presence of the culture medium is very difficult which may require the withdrawal of culture medium before completion of the cultivation cycle.

\subsection{Bioremediation efficiency}

Bioremediation efficiency was estimated only of the wastewater used in outdoor systems (PBR3 and PBR4) because outdoor systems outperformed indoor systems in terms of productivity, energy consumption, and cost. After that was found, bioremediation efficiency was compared with the wastewater treatment efficiency of the AIT wastewater plant. Algal biomass density of PBR3 and PBR4 reached highest after 4 and 6 days, respectively, but algal growth pattern in the outdoor system was observed for 10 days. The wastewater inside of PBR3 and PBR4 went through bioremediation continuously for 10 days. Details of bioremediation of PBR3 and PBR4 along with wastewater treatment efficiency of AIT wastewater treatment plant are reported in Table 5. The complete removal of BOD, COD, and TP was successfully achieved in both PBR3 and PBR4, whereas BOD and COD removal efficiency of the wastewater treatment plant was $70.38 \%$ and $90.65 \%$, respectively. Furthermore, $99.28 \%$ and $98.01 \%$ TKN, $92.02 \%$, and $80.63 \%$ nitrate and nitrite and $98.5 \%$ and $96.1 \%$ TN were removed from the wastewater used in PBR3 and PBR4, respectively. TKN removal efficiency of the wastewater treatment plant in AIT was $72.98 \%$, lower than both outdoor PBRs in this study. AIT treatment plant does not measure TP, TN, nitrite, and nitrate. Although the overall bioremediation performance of PBR3 was slightly better than of PBR4, both of them displayed significantly higher pollutants removal capacity than of the wastewater treatment plant. However, the downside of bioremediation in algal cultivation systems is that it requires more time and energy. Wastewater treatment plant treats all wastewater collected in its collector tank in just 1 day; it also can be operated continuously. Nevertheless, in this experiment, all PBRs were batch, and the residence time of wastewater in outdoor PBRs was 10 days, 10 times higher than the wastewater treatment plant. The plant consumed 0.44 Wh energy for treating 1-I wastewater, 82 times lower than each outdoor PBR.
Table 5 Comparison of the efficiency of AIT wastewater treatment plant and outdoor PBRs

\begin{tabular}{|c|c|c|c|}
\hline Contents & $\begin{array}{l}\text { Treatment } \\
\text { plant } \\
\text { effluent }\end{array}$ & PBR3 & PBR4 \\
\hline $\begin{array}{l}\text { BOD removal percentage } \\
(\%)\end{array}$ & 70.38 & $100 \pm 0.00$ & $100 \pm 0.00$ \\
\hline $\begin{array}{l}\text { COD removal percentage } \\
(\%)\end{array}$ & 90.65 & $100 \pm 0.00$ & $100 \pm 0.00$ \\
\hline $\begin{array}{l}\text { TKN removal percentage } \\
\text { (\%) }\end{array}$ & 72.98 & $99.28 \pm 0.16$ & $98.01 \pm 0.24$ \\
\hline $\begin{array}{l}\text { Nitrite and nitrate removal } \\
\text { percentage (\%) }\end{array}$ & - & $92.02 \pm 0.21$ & $80.63 \pm 0.09$ \\
\hline TN removal percentage (\%) & - & $98.51 \pm 0.14$ & $96.11 \pm 0.22$ \\
\hline TP removal percentage (\%) & - & $100 \pm 0.00$ & $100 \pm 0.00$ \\
\hline Total time required (days) & 1 & 10 & 10 \\
\hline Total energy required (Wh/l) & 0.44 & 36.0 & 36.0 \\
\hline
\end{tabular}

While there are many studies available on microalgae about nutrient removal from wastewater used in indoor PBRs in literature, limited studies on outdoor PBRs have been found. TN and TP removal were found maximum up to $90 \%$ and $100 \%$, respectively, in indoor PBRs [20,29, 30]. Several studies claim that algal systems integrated with different types of wastewater, i.e., brewery wastewater, swine wastewater, municipal wastewater, etc., 90-100\% BOD, $60-99.9 \%$ COD, $99.96 \%$ TP, $100 \%$ total carbon and $40-90 \%$ ammonium nitrogen [31-33]. Nutrient removal from wastewater depends on algal growth, characteristics of wastewater, the quantity of nutrients and pollutants, incubation period, etc. Usually, very high nutrient removal efficiency is not required from wastewater unless the purpose of treatment is to produce drinking water or water for domestic or industrial usage where water purity is required to be very high. The effluent discharge standard varies from country to country also, such as in Bangladesh "Department of Environment" approved BOD and COD limit of effluent is 50 ppm and 200 ppm [34], respectively, and in Germany "Federal Environment Agency" approved BOD and COD limit of municipal wastewater effluent is $15 \mathrm{ppm}$ and 75 ppm [35]. Energy consumption and operation cost of a traditional treatment plant could be changed with change of effluent standard; higher standard requires higher degree of nutrient removal requiring higher cost. But with the result found in this study, bioremediation of outdoor algal cultivation can fit with any standard of wastewater treatment. 


\section{Conclusion}

This study recommends for outdoor systems over indoor systems for microalgae cultivation in PBRs in tropical regions. Seasonal weather changes would affect algal productivity. Experimentation in different conditions, i.e., cold weather and in the rainy season will help to understand the nature of algal growth throughout the year. The integration of wastewater with an algal cultivation system is recommended because of achieved high bioremediation efficiency in this study. Higher energy and time requirements may cause concern; however, it should be noted that in commercial algal cultivation system bioremediation takes place simultaneously and is part and parcel of algal biomass production, whereas in the wastewater treatment plant the treated effluent has no value addition and the produced sludge is dumped to landfill. $\mathrm{pH}$ control is recommended, and manual $\mathrm{pH}$ control is preferred because of lower energy and money requirement. Lower concentrations of $\mathrm{CO}_{2}$ and continuous aeration are also recommended for smooth operation. Adequate light transmission efficiency, durability, and low cost make PET a standard material of PBR for simple operations. Simple PBR type and operation mechanism was used in this experiment. Better algal growth can be found by more developed PBR and complex operation mechanisms, but in that case, both operation and capital costs will increase.

Acknowledgements Authors express their gratitude to Ranhill Water Technologies (Thai) Ltd. for allowing to collect wastewater and providing relevant data and the Thailand Institute of Scientific and Technological Research (TISTR) for providing pure microalgae strain.

\section{Compliance with ethical standards}

Conflict of interest The authors declare that they have no conflict of interest.

\section{References}

1. Chen $\mathrm{P}, \mathrm{Min} \mathrm{M}, \mathrm{Chen} \mathrm{Y}$ et al (2010) Review of biological and engineering aspects of algae to fuels approach. Int J Agric Biol Eng 2(4):1-30. https://doi.org/10.25165/IJABE.V2/4.200

2. Harun R, Singh M, Forde GM, Danquah MK (2010) Bioprocess engineering of microalgae to produce a variety of consumer products. Renew Sustain Energy Rev 14(3):1037-1047. https:// doi.org/10.1016/J.RSER.2009.11.004

3. Bishop WM, Zubeck HM (2012) Evaluation of microalgae for use as nutraceuticals and nutritional supplements. J Nutr Food Sci 02(05):1-6. https://doi.org/10.4172/2155-9600.1000147

4. Spolaore P, Joannis-Cassan C, Duran E, Isambert A (2006) Commercial applications of microalgae. J Biosci Bioeng 101(2):87-96. https://doi.org/10.1263/JBB.101.87

5. Wahlen BD, Willis RM, Seefeldt LC (2011) Biodiesel production by simultaneous extraction and conversion of total lipids from microalgae, cyanobacteria, and wild mixed-cultures. Biores Technol 102(3):2724-2730. https://doi.org/10.1016/J.BIORT ECH.2010.11.026

6. Demirbas MF, Balat M, Balat H (2011) Biowastes-to-biofuels. Energy Convers Manag 52(4):1815-1828. https://doi. org/10.1016/J.ENCONMAN.2010.10.041

7. Sayre R (2010) Microalgae: the potential for carbon capture. Bioscience 60(9):722-727. https://doi.org/10.1525/ bio.2010.60.9.9

8. Sarker NK (2016) Theoretical effect of concentration, circulation rate, stages, pressure and temperature of single amine and amine mixture solvents on gas sweetening performance. Egypt J Pet 25(3):343-354. https://doi.org/10.1016/J.EJPE.2015.08.004

9. Guiry MD (2012) How many species of algae are there? J Phycol 48(5):1057-1063. https://doi.org/10.111 1/j.1529-8817.2012.01222.x

10. Guccione A, Biondi N, Sampietro G et al (2014) Chlorella for protein and biofuels: from strain selection to outdoor cultivation in a Green Wall Panel photobioreactor. Biotechnol Biofuels 7(1):84. https://doi.org/10.1186/1754-6834-7-84

11. Becker EW (1994) Microalgae: biotechnology and microbiology. Cambridge University Press, Cambridge

12. Pulz O, Gross W (2004) Valuable products from biotechnology of microalgae. Appl Microbiol Biotechnol 65(6):635-648. https ://doi.org/10.1007/s00253-004-1647-x

13. Srisuwan P, Shoichi K (2017) Field investigation on indoor thermal environment of a high-rise condominium in hot-humid climate of Bangkok, Thailand. Procedia Eng 180:1754-1762. https ://doi.org/10.1016/J.PROENG.2017.04.338

14. Waewsak J, Chancham C, Mani M, Gagnon Y (2014) Estimation of monthly mean daily global solar radiation over Bangkok, Thailand using artificial neural networks. Energy Procedia 57:11601168. https://doi.org/10.1016/J.EGYPRO.2014.10.103

15. Mayo AW (1997) Effects of temperature and $\mathrm{pH}$ on the kinetic growth of unialga Chlorella vulgaris cultures containing bacteria. Water Environ Res 69:64-72. https://doi.org/10.2307/25044843

16. Liang Y, Sarkany N, Cui Y (2009) Biomass and lipid productivities of Chlorella vulgaris under autotrophic, heterotrophic and mixotrophic growth conditions. Biotechnol Lett 31(7):1043-1049. https://doi.org/10.1007/s10529-009-9975-7

17. Eaton AD, Franson MAH, Clesceri LS et al (2005) Standard methods for the examination of water \& wastewater, 21st edn. American Public Health Association, Washington, DC

18. Thimijan RW, Heins RD (1983) Photometric, radiometric, and quantum light units of measure: a review. HortScience 18(6):818-822

19. Frumento D, Casazza AA, Al Arni S, Converti A (2013) Cultivation of Chlorella vulgaris in tubular photobioreactors: a lipid source for biodiesel production. Biochem Eng J 81:120-125. https://doi. org/10.1016/J.BEJ.2013.10.011

20. Singh R, Birru R, Sibi G (2017) Nutrient removal efficiencies of Chlorella vulgaris from urban wastewater for reduced eutrophication. J Environ Prot 08(01):1-11. https://doi.org/10.4236/ jep.2017.81001

21. Lam MK, Lee KT (2014) Cultivation of Chlorella vulgaris in a pilotscale sequential-baffled column photobioreactor for biomass and biodiesel production. Energy Convers Manag 88:399-410. https://doi.org/10.1016/J.ENCONMAN.2014.08.063

22. Sakarika M, Kornaros M (2016) Effect of pH on growth and lipid accumulation kinetics of the microalga Chlorella vulgaris grown heterotrophically under sulfur limitation. Biores Technol 219:694-701. https://doi.org/10.1016/J.BIORTECH.2016.08.033

23. Rachlin JW, Grosso A (1991) The effects of pH on the growth of Chlorella vulgaris and its interactions with cadmium toxicity. Arch Environ Contam Toxicol 20(4):505-508. https://doi. org/10.1378/chest.119.4.1151 
24. Kamsamrong J, Sorapipatana $\mathrm{C}$ (2014) Assessing $\mathrm{CO}_{2}$ abatement cost for Thailand's power generation. J Sustain Energy Environ 5:21-26

25. Sharma KK, Schuhmann H, Schenk PM et al (2012) High lipid induction in microalgae for biodiesel production. Energies 5(5):1532-1553. https://doi.org/10.3390/en5051532

26. Guckert JB, Cooksey KE (1990) Triglyceride accumulation and fatty acid profile changes in Chlorella (chlorophyta) during high ph-induced cell cycle inhibition. J Phycol 26(1):72-79. https:// doi.org/10.1111/j.0022-3646.1990.00072.x

27. Gardner R, Peters P, Peyton B, Cooksey KE (2011) Medium pH and nitrate concentration effects on accumulation of triacylglycerol in two members of the chlorophyta. J Appl Phycol 23(6):10051016. https://doi.org/10.1007/s10811-010-9633-4

28. Cuellar-Bermudez SP, Aguilar-Hernandez I, Cardenas-Chavez DL et al (2015) Extraction and purification of high-value metabolites from microalgae: essential lipids, astaxanthin and phycobiliproteins. Microb Biotechnol 8(2):190-209. https://doi. org/10.1111/1751-7915.12167

29. López YC, Marín AR, del Carmen Zavala-Loría J (2016) A twostage culture process using Chlorella vulgaris for urban wastewater nutrient removal and enhanced algal lipid accumulation under photoautotrophic and mixotrophic conditions. J Renew Sustain Energy 8(3):033102. https://doi.org/10.1063/1.4954078

30. Mirquez LD, Lopes F, Taidi B, Pareau D (2016) Nitrogen and phosphate removal from wastewater with a mixed microalgae and bacteria culture. Biotechnol Rep 11:18-26. https://doi. org/10.1016/J.BTRE.2016.04.003

31. Wang Y, Guo W, Yen H-W et al (2015) Cultivation of Chlorella vulgaris JSC- 6 with swine wastewater for simultaneous nutrient/COD removal and carbohydrate production. Biores Technol 198:619-625. https://doi.org/10.1016/J.BIORTECH.2015.09.067

32. Choi H-J (2016) Parametric study of brewery wastewater effluent treatment using Chlorella vulgaris microalgae. Environ Eng Res 21(4):401-408. https://doi.org/10.4491/eer.2016.024

33. Ahmad F, Khan AU, Yaşar A (2013) The potential of Chlorella vulgaris for wastewater treatment and biodiesel production. Pak J Bot 45(S1):461-465

34. Sarker NK, Sarkar S (2018) A comparative study on cost analysis, efficiency, and process mechanism of effluent treatment plants in Bangladesh. Environ Qual Manag 27(3):127-133. https://doi. org/10.1002/tqem.21533

35. BONUS OPTITREAT (2017) Maintenance regulation of small wastewater treatment facilities. Stockholm

Publisher's Note Springer Nature remains neutral with regard to jurisdictional claims in published maps and institutional affiliations. 